of liver,abnormal fat metabolism and hemophagocytosis were common clinical features. Two cases were with ARDS and MOF in three and three died. The perforin A91V (NCBI:SNP rs35947132) gene was detected in seven systemic onset juvenile idiopathic arthritis compolicated with MAS cases, but no mutation were found. Glucocorticoid, intravenous immunoglobulin, immunoimpressive therapy were effective and HP (Plasmapheresis) used in one serious case was also effective.

Conclusions: MAS is a rare and potentially fatal complication of childhood rheumatoid diseases,especially systemic onset juvenile idiopathic arthritis. Most of our patients were male, and most cases were preceded by infection. Bone marrow studies support the diagnosis. MOF may be a poor prognostic sign.Aggressive early therapy is essential.

Disclosure of Interest: None declared

DOI: 10.1136/annrheumdis-2017-eular.1791

\section{AB0287 MUTUAL ASSENT TOWARDS COMPREHENSIVE DISEASE CONTROL: THE RELATIONSHIP BETWEEN US MEASURES AND PATIENT REPORTED OUTCOMES IN EARLY RHEUMATOID ARTHRITIS}

Y. El Miedany ${ }^{1}$, M. El Gaafary ${ }^{2}$, N. El Arousi ${ }^{3}$, S.S. Youssef ${ }^{3}$, A. Nasr ${ }^{4}$ ${ }^{1}$ Rheumatology, Darent Valley Hospital, Dartford, United Kingdom; ${ }^{2}$ Community and Public health; ${ }^{3}$ Rheumatology and Rehabilitation; ${ }^{4}$ Radiology, Ain Shams University, Cairo, Egypt

Objectives: Assessment of the relationship between US measures of joint inflammation/damage and patient reported outcomes (PROs): HAQ, pain and patient global assessment in early rheumatoid arthritis (early RA) patients over 5 -years follow up period.

Methods: This longitudinal cohort of 261 patients with early RA was derived from the US monitoring study [1]. Adopting OMERACT definitions; correlations between total US scores (synovial hypertrophy, synovial fluid, Power Doppler, bone erosion and tenosynovitis) and PROs [2] namely functional disability (HAQ), pain and patient global scores were determined at 0, 1, and 5years. Radiological damage was assessed using modified Total Sharp score (mTSS). Univariate correlations as well as correlations between interval changes were assessed. Multivariable regression models were used to evaluate the associations over all time-points and their relationship to clinical disease activity measures.

Results: There were significant correlations $(p<0.01)$ between total US score and HAQ $(r=0.71)$, pain $(r=0.69)$ and patient global scores $(r=0.66)$ at all timepoints. The association tends to be stronger with increase disease duration (Spearman correlation 0.12 at baseline, 0.22 at 1 -year and 0.41 at 5 -years). Change in mTSS score at 5 -years was not associated with changes in PROs. Improvements in US scores were also associated with improvements in PROs. Multivariate models revealed that synovial hypertrophy and Power Doppler scores were associated $(p<0.01)$ with functional disability, pain and patient global assessment, controlling for clinical disease activity measures. Studying the pattern of joint involvement, it was associated significantly $(p<0.01)$ with the US score of the affected joints. US total score at 1 -year predicted subsequent 5 -year $\mathrm{HAQ}$ score $(\mathrm{R} 2=0.17)$. At 0,1 and 5-years, total US scores were higher in patients whose HAQ score was $>1$ (9.26) compared to those below $1(4.16, p<0.01)$.

Conclusions: the link between joint inflammation/structural damage and PROs is of critical importance to the care of patients with inflammatory arthritis. US measures of inflammation and structural damage correlated independently with physical function, pain and patient global assessments. A clear relationship between radiographic structure damage and the patient's perceived remission/flare provide the basis for comprehensive disease assessment and management. References:

[1] El Miedany et al. Current Rheumatology Reviews 2015; 11, 18-27.

[2] El Miedany et al. Clin Exp Rheumatol 2010; 28(5):734-44.

Disclosure of Interest: None declared

DOI: 10.1136/annrheumdis-2017-eular.4485

\section{AB0288 LABORATORY MARKERS OF INFLAMMATION AND SERUM NICOTINAMIDE PHOSPHORIBOSYLTRANSFERASE LEVEL IN RHEUMATOID ARTHRITIS PATIENTS}

Y. Akhverdyan ${ }^{1}$, B. Zavodovsky ${ }^{1}$, J. Polyakova ${ }^{1}$, L. Seewordova ${ }^{1}$ I. Zborovskaya ${ }^{1}$, T. Rogatkina ${ }^{2} .{ }^{1}$ Federal State Budgetary Institution "Research Institute of Clinical and Experimental Rheumatology" Under the Russion Academy of Medical Sciences, ${ }^{2}$ Volgograd State Medical University, Volgograd, Russian Federation

Objectives: To study relationship between serum levels of nicotinamide phosphoribosyltransferase and laboratory markers of inflammation in patients with rheumatoid arthritis (RA).

Methods: We determined nicotinamide phosphoribosyltransferase level in sera of 140 patients with RA ( 96 women and 44 men) by indirect enzyme-linked immunosorbent assay (RaiBiotech, cat No. EIA-VIS-1). The control group consisted of 20 women and 10 men aged 22 to 55 years without complaints of pain in the joints throughout life. The mean duration of disease was $5.94 \pm 0.37$ years.

Results: We divided all RA patients into 2 groups: one group (118 patients) with elevated levels of nicotinamide phosphoribosyltransferase serum (more than 3.9 $\mathrm{ng} / \mathrm{ml}$ ) and second group (22 patients) - with normal range.

In each of the two groups, the levels of CRP and ESR were determined.

Patients with elevated levels of Nampt had the following laboratory parameters $(\mathrm{M} \pm \mathrm{m})$ : $\mathrm{ESR}-37.83 \pm 1,57$, CRP $-56.09 \pm 3,73$ (rate - less than $5.0 \mathrm{mg} / \mathrm{l}$ ). The second group had following data: ESR $22.46 \pm 0,56$, CRP 21,65 \pm 1.38 . Thus, patients with elevated levels of nicotinamide phosphoribosyltransferase had significantly higher concentrations of ESR and CRP $(p<0,001)$.

Conclusions: There is the relationship between the level of nicotinamide phosphoribosyltransferase serum and laboratory markers of inflammation in RA (CRP and ESR). The data indirectly confirm the hypothesis that increased levels of nicotinamide phosphoribosyltransferase in RA patients is associated with disease activity.

Disclosure of Interest: None declared

DOI: 10.1136/annrheumdis-2017-eular.1958

\section{AB0289 PREDICTOR OF THE SIMPLIFIED DISEASE ACTIVITY INDEX 50 (SDAI 50) AT MONTH 6 DURING BDMARDS TREATMENT IN PATIENTS WITH LONG-ESTABLISHED RHEUMATOID ARTHRITIS: A SINGLE-CENTER, RETROSPECTIVE STUDY}

Y. Miwa, A. Nishimi, S. Nishimi, T. Tokunaga, S. Ishii, T. Kasama on behalf of ASHURA Registry Group. Division of Rheumatology, Department of Medicine, Showa University School of Medicine, Tokyo, Japan

Background: The simplified disease activity index (SDAI) 50 has good agreement with the EULAR response measures for early rheumatoid arthritis (RA). Although there are reports on early RA, there have been no reports on long-established RA. Objectives: In this study, we analyzed the relationships between various baseline factors and SDAI 50 after six months of biological disease-modifying antirheumatic drugs (bDMARDs) treatment to determine the prognostic factors for long-established RA.

Methods: The subjects were 332 RA patients who had been treated with bDMARDs for 6 months. The following characteristics were investigated: age, gender, disease duration, smoking history, body mass index, steroid and methotrexate dosage, previous bDMARDs use, combined csDMARDs use, ESR, CRP, serum matrix metalloproteinase-3 levels, SDAI score, health assessment questionnaire disability index score (for daily living activities) and short form-36 score (for quality of life). As a primary outcome index, SDAI response was defined as a $50 \%$ reduction in SDAI score between baseline and 6 months (SDAI 50).

Results: The group of RA patients who achieved SDAI 50 (Group A: 204 patients) had a higher tender joint count $(p=0.041)$, swollen joint count $(p=0.001)$, evaluator's global assessment $(p=0.027)$ and SDAI $(p=0.006)$ than did those who did not achieve SDAI 50 (Group B: 152 patients). Before the start of the treatment, steroid dosage $(p=0.0187$, odds ratio: $1.119,95 \% \mathrm{Cl}: 1.029-1.229)$ and SDAI $(p=0.0003$, odds ratio: $0.953,95 \% \mathrm{Cl}: 0.928-0.978$ ) were determined based on logistic regression analysis. Comparisons were performed between Groups A and $B$ and between before treatment and after 6 months of SDAI. Group A showed a significant improvement compared to Group B by repeated measure analysis of variance (ANOVA) (Interaction: $p=0.000$, Group A vs. Group B: $p=0.000$, before vs. after treatment: $p=0.000)$.

Conclusions: Our study demonstrated that RA patients with a lower steroid dosage and higher SDAl baseline are more likely to achieve SDAI 50 with bDMARD treatment.

Acknowledgements: ASHURA Resistry Groups

Disclosure of Interest: Y. Miwa Grant/research support from: Astellas Pharma Inc., Mitsubishi Tanabe Pharma Corporation, AbbVie CK, Pfizer Japan Inc., Chugai Pharmaceutical Co., Ltd., Eizai Co., Ltd, Asahi Kasei Pharm Co., Ltd, YL biologics Ltd., Japan Blood Products Organization,. Ono Pharmaceutical Co., Ltd., Nippon Kayaku Co., Ltd., and Teijin Pharma Ltd., A. Nishimi: None declared, S. Nishimi: None declared, T. Tokunaga: None declared, S. Ishii: None declared, T. Kasama Grant/research support from: Mitsubishi Tanabe Pharma Corporation and AbbVie CK.

DOI: 10.1136/annrheumdis-2017-eular.1818

\section{Rheumatoid arthritis - comorbidity and clinical aspects}

\section{AB0290 PULMONARY AMYLOIDOSIS IN RHEUMATOID ARTHRITIS - A} POSTMORTEM CLINICOPATHOLOGIC STUDY OF 161 PATIENTS

Á. Apáthy ${ }^{1}$, M. Bély ${ }^{2}$. ${ }^{1}$ Department of Rheumatology, St. Margaret Clinic Budapest; ${ }^{2}$ Department of Pathology, Hospital of the Order of the Brothers of Saint John of God, Budapest, Hungary

Background: AA amyloidosis ( $A A a$ ) is one of the most insidious systemic complications of rheumatoid arthritis (RA), which furtively may lead to death [1]. Objectives: The aim of this study was to determine the prevalence and location of amyloid A deposition in the lungs of RA patients at the time of death.

Methods: A randomized autopsy population of 161 in-patients with RA was studied. AAa complicated RA in $34(21.1 \%)$ cases [1]. 